\title{
DABN Borazabicycles: Formation from MIDA Boronates and Synthetic Utility
}

Sherif J. Kaldas, ${ }^{\mathrm{a}}$ Chieh-Hung Tien, ${ }^{\mathrm{a}}$ Gabriel dos Passos Gomes, ${ }^{\mathrm{c}, \mathrm{d}}$ Stephanie Meyer, ${ }^{\mathrm{a}}$ Martynas Sirvinskas, ${ }^{\mathrm{a}}$ Hayden Foy, ${ }^{\mathrm{b}}$ Travis Dudding, ${ }^{\mathrm{b}}$ and Andrei K. Yudin ${ }^{\mathrm{a}}$

${ }^{a}$ Davenport Research Laboratories, Department of Chemistry, University of Toronto, $80 \mathrm{St}$. George St. Toronto, ON, M5S 3H6, Canada

${ }^{b}$ Department of Chemistry, Brock University, 1812 Sir Isaac Brock Way, St. Catharines, ON L2S

3A1, Canada

${ }^{\mathrm{c} C h e m i c a l ~ P h y s i c s ~ T h e o r y ~ G r o u p, ~ D e p a r t m e n t ~ o f ~ C h e m i s t r y, ~ U n i v e r s i t y ~ o f ~ T o r o n t o, ~ T o r o n t o, ~}$ Ontario, M5S 3H6, Canada

${ }^{\mathrm{d}}$ Department of Computer Science, University of Toronto, 214 College St., Toronto, Ontario M5T 3A1, Canada.

\begin{abstract}
Herein we report that coordinative hemilability allows the MIDA nitrogen to behave as a nucleophile to intramolecularly intercept palladium $\pi$-allyl intermediates. A mechanistic investigation indicates that this rearrangement proceeds through an $\mathrm{S}_{\mathrm{N}}$ 2-like displacement at tetrasubstituted boron to furnish novel DABN (2,8-dioxa-5-aza-1-borabicyclo[3.3.1]nonane-3,7dione) boronates. Oxidative addition into the $\mathrm{N}-\mathrm{C}$ bond of the $\mathrm{DABN}$ scaffold reverses the reaction and furnishes borylated $\pi$-allyl intermediates that can then be trapped with complete linear selectivity. DFT calculations indicate that stabilizing interactions in the transition state, as well as the steric bulk of the MIDA unit, are the origins of the observed regioselectivity. We further demonstrate the utility of our new reagents through 3-component coupling that features allylammonium DABN boronates as linchpin reagents. This report disseminates a previously unknown aspect of MIDA boronates that can now be exploited. We anticipate that a number of other mechanisms that involve MIDA might be revised to accommodate for this possibility.
\end{abstract}




\section{Introduction}

The stability of MIDA ( $N$-methyliminodiacetic acid) boronates stems from the attenuation of boron's Lewis acidity by a dative nitrogen-boron bond. ${ }^{1-10}$ Under most conditions, the nitrogen atom remains coordinated to the boron center until the MIDA ligand is hydrolyzed by aqueous base. ${ }^{4,11-13}$ This stability has resulted in MIDA becoming the ligand of choice for protecting unstable boronic acids in applications like the development of amphoteric boronates. ${ }^{14,15}$ Despite the stability of the MIDA ligand, our group has demonstrated that under certain conditions, the pendant amine displays hemilabile character. ${ }^{16,17}$ This allows the MIDA ligand to switch between nucleophilic and electrophilic reactivity at the boron center (Figure 1A). ${ }^{16}$ Utilizing this dichotomous behavior our group has reported methodology for the synthesis of novel boronates through either electrophilic or nucleophilic migrations, such as the bora-Cope, bora-Peterson and bora-Baeyer-Villiger reactions. ${ }^{16}$

\section{A) MIDA Hemilability:}
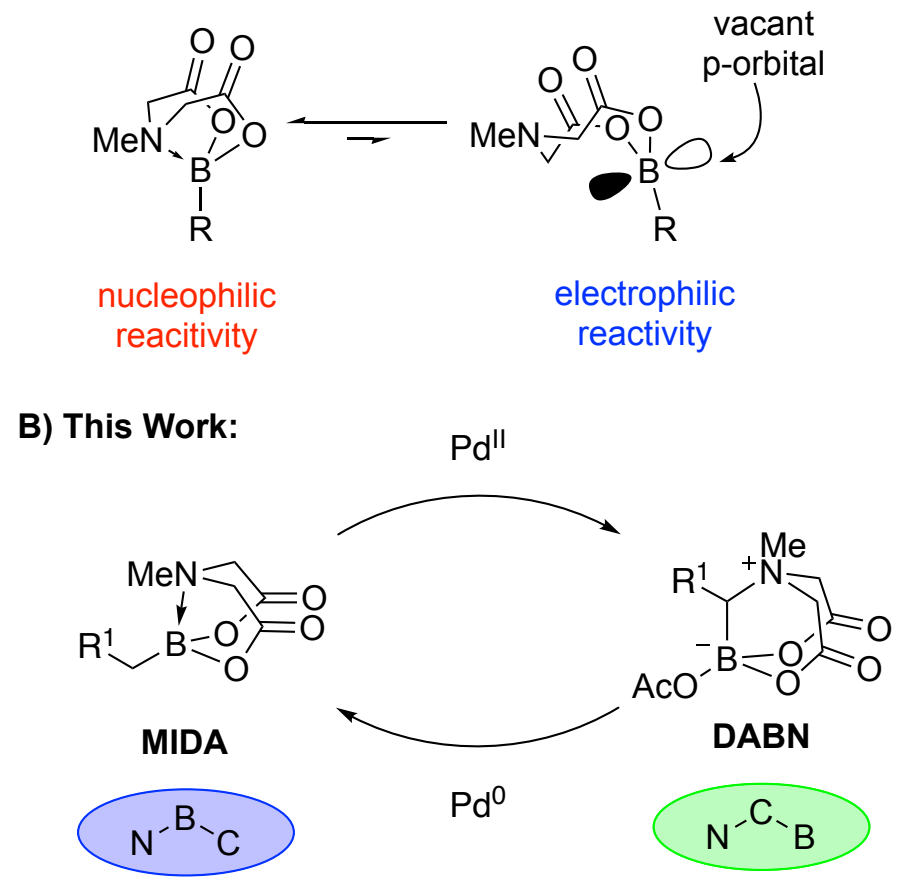

Figure 1. A) Amine coordination enables the MIDA moiety to migrate as either a nucleophile or as an electrophile. B) MIDA amine can function as a nucleophile after decoordination from boron. This process involves rearrangement from an N-B-C to a B-C-N connectivity. 
We now report a new reactivity mode of the MIDA ligand that proceeds via a skeletal rearrangement. During this reaction, the MIDA amine decoordinates from boron and attacks the adjacent carbon center to furnish a ring expanded DABN system (2,8-dioxa-5-aza-1borabicyclo[3.3.1] nonane-3,7-dione, Scheme 1B). As a result, the connectivity changes from an $\mathrm{N}-\mathrm{B}-\mathrm{C}$ to an N-C-B motif. This subtle one atom swap removes the stabilizing effects of amine coordination to boron but now offers a new synthetic handle. Specifically, oxidative addition by $\mathrm{Pd}^{0}$ into the newly formed $\mathrm{C}-\mathrm{N}$ bond is now possible. After palladium insertion, coordination of the amine to boron is restored with concomitant formation of a borylated $\pi$-allyl system. This reversible coordination enables the synthesis of a variety of useful boron-based building blocks.

\section{Results and Discussion}

During oxidation of allyl MIDA boronate (1) utilizing the White catalytic system, ${ }^{18-21} \mathbf{2 a}$ was obtained in 55\% yield as the major product of the reaction (Scheme 1). Linear allyl acetate (3) was only formed in 25\% yield, and branched acetate (4) was not observed. Compound 2 a contains the DABN scaffold, which forms through decoordination of the MIDA amine and subsequent attack onto the internal allylic carbon.

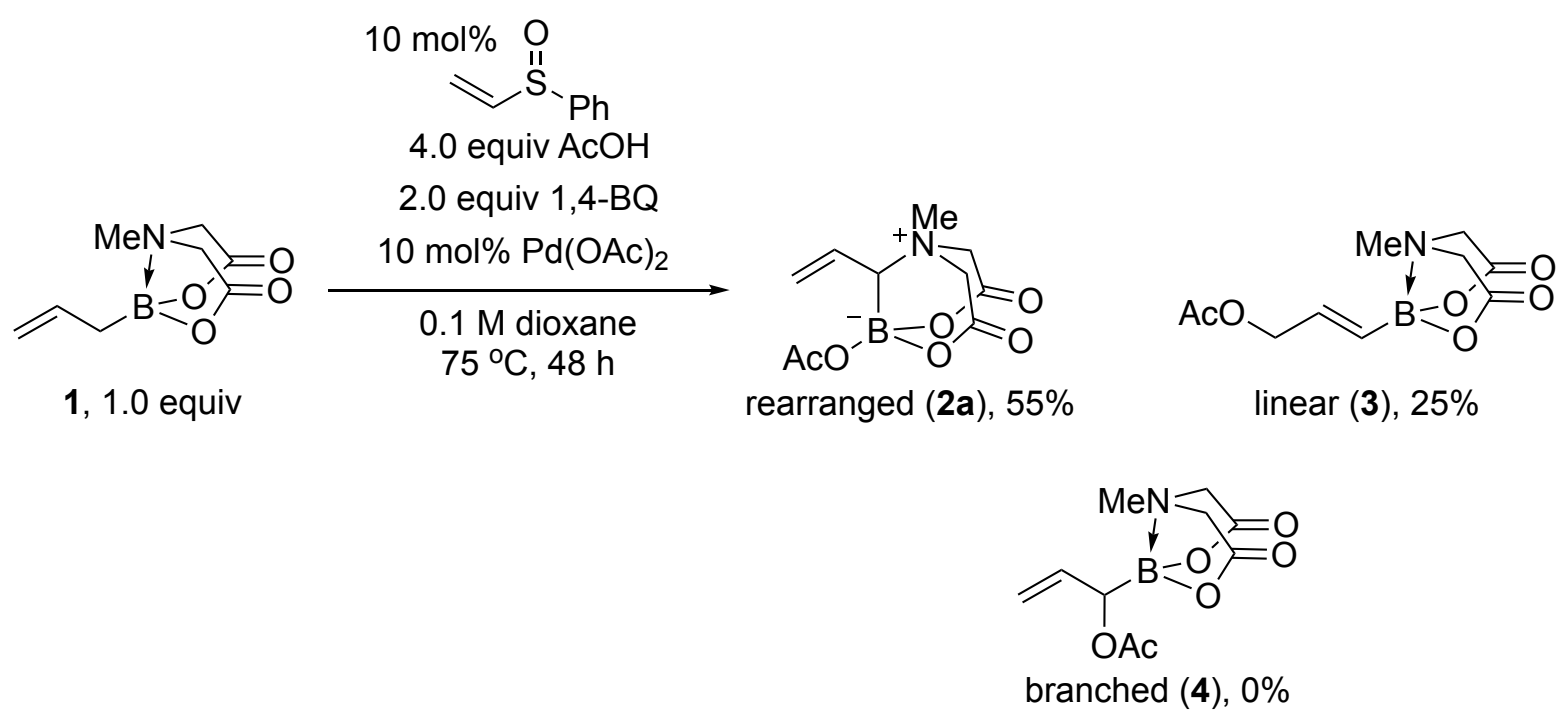

Scheme 1. Interrupted allylic acetoxylation furnishes rearranged DABN allylammonium boronate $\mathbf{2 a}$. 
Our optimized conditions were found by switching the ligand from phenylvinylsulfoxide to 1,2bis(phenylsulfinyl)ethane and maintaining the reaction temperature at $75^{\circ} \mathrm{C}$ (Table 1 , entry 2 ). This condition furnished the product in 85\% NMR yield and with only trace amounts of the linear product (3). Lower yield and selectivity were observed when decreasing the amount of acetic acid to 1.5 equivalents (entry 3 ). While increasing the amount of acetic acid to 8 or 16 equivalents (entries 4 and 5) did not have a significant impact on regioselectivity but did decrease the yield slightly to $71 \%$ and $70 \%$, respectively. Lowering the catalyst loading to $5 \mathrm{~mol} \%$ reduced the yield and selectivity of the reaction (entry 6). Using 1 equivalent of 1,4-benzoquinone (entry 7) negatively affected the yield (68\%), but did not erode regioselectivity. Switching the solvent to chloroform (entry 8) caused a complete reversal of regioselectivity, favoring the linear product (3) in $50 \%$ yield and with $>20: 1$ selectivity compared to 2a. Finally, utilizing potassium allyltrifluoroborate (entry 9) or allylboronic acid pinacol ester (entry 10) resulted in a complex mixture of products. 
Table 1. Optimization of the allylic oxidation/MIDA rearrangement reaction of $\mathbf{1}$ to $\mathbf{2 a}$.

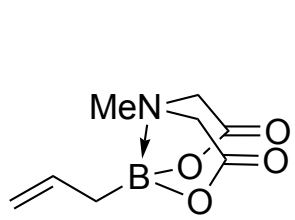

1, 1.0 equiv $^{\mathrm{a}}$
$\mathrm{AcOH}$ ( $\mathrm{X}$ equiv)

1,4-benzoquinone ( $X$ equiv)

$\mathrm{Pd}(\mathrm{OAc})_{2}(\mathrm{X} \mathrm{mol} \%)$

sulfoxide $(10 \mathrm{~mol} \%)$

dioxane $(0.1 \mathrm{M})$

$\mathrm{T}\left({ }^{\circ} \mathrm{C}\right), 48 \mathrm{~h}$

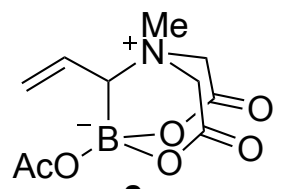

$+$

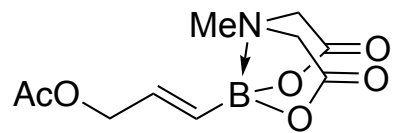

3

\begin{tabular}{|c|c|c|c|c|}
\hline Entry & Sulfoxide & {$[\mathrm{B}]$} & Conditions & $\%$ Yield, $2 \mathrm{a}: \mathbf{3}^{\mathrm{b}}$ \\
\hline 1 & $\mathrm{Ph}^{-\mathrm{S}}$ & BMIDA & $\begin{array}{c}10 \% \mathrm{Pd}(\mathrm{OAc})_{2} \\
4.0 \text { equiv } \mathrm{AcOH}, 2.0 \text { equiv } 1,4-\mathrm{BQ} \\
40^{\circ} \mathrm{C}\end{array}$ & $0,2: 1$ \\
\hline 2 & h' & BMIDA & $\begin{array}{c}10 \% \mathrm{Pd}(\mathrm{OAc})_{2} \\
4.0 \text { equiv } \mathrm{AcOH}, 2.0 \text { equiv } 1,4-\mathrm{BQ} \\
75^{\circ} \mathrm{C}\end{array}$ & $85,>25: 1^{\mathrm{c}}$ \\
\hline 3 & & BMIDA & $\begin{array}{c}10 \% \mathrm{Pd}(\mathrm{OAc})_{2} \\
1.5 \text { equiv } \mathrm{AcOH}, 2.0 \text { equiv } 1,4-\mathrm{BQ} \\
75^{\circ} \mathrm{C}\end{array}$ & $60,11: 1$ \\
\hline 4 & & BMIDA & $\begin{array}{c}10 \% \mathrm{Pd}(\mathrm{OAc})_{2} \\
8.0 \text { equiv } \mathrm{AcOH}, 2.0 \text { equiv } 1,4-\mathrm{BQ} \\
75^{\circ} \mathrm{C}\end{array}$ & $71,>25: 1$ \\
\hline 5 & & BMIDA & $\begin{array}{c}10 \% \mathrm{Pd}(\mathrm{OAc})_{2} \\
16.0 \text { equiv } \mathrm{AcOH}, 2.0 \text { equiv } 1,4-\mathrm{BQ} \\
75^{\circ} \mathrm{C}\end{array}$ & $70,>25: 1$ \\
\hline 6 & & BMIDA & $\begin{array}{c}5 \% \mathrm{Pd}(\mathrm{OAc})_{2} \\
4.0 \text { equiv } \mathrm{AcOH}, 2.0 \text { equiv } 1,4-\mathrm{BQ} \\
75^{\circ} \mathrm{C}\end{array}$ & $30,10: 1$ \\
\hline 7 & & BMIDA & $\begin{array}{c}10 \% \mathrm{Pd}(\mathrm{OAc})_{2} \\
4.0 \text { equiv } \mathrm{AcOH}, 1.0 \text { equiv } 1,4-\mathrm{BQ} \\
75^{\circ} \mathrm{C}\end{array}$ & $68,>25: 1$ \\
\hline 8 & & BMIDA & $\mathrm{CHCl}_{3}$ instead of Dioxane & $50,>1: 25$ \\
\hline 9 & & $\mathrm{BF}_{3} \mathrm{~K}$ & $\begin{array}{c}10 \% \mathrm{Pd}(\mathrm{OAc})_{2} \\
4.0 \text { equiv } \mathrm{AcOH}, 2.0 \text { equiv } 1,4-\mathrm{BQ} \\
75^{\circ} \mathrm{C}\end{array}$ & $-^{d}$ \\
\hline 10 & & BPin & $\begin{array}{c}10 \% \mathrm{Pd}(\mathrm{OAc})_{2} \\
4.0 \text { equiv } \mathrm{AcOH}, 2.0 \text { equiv } 1,4-\mathrm{BQ} \\
75^{\circ} \mathrm{C}\end{array}$ & $-^{d}$ \\
\hline
\end{tabular}

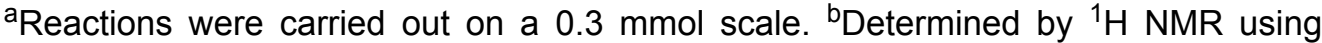
dibromomethane as internal standard. 'Reaction furnished 3 in 50\% yield, with $>20: 1$ selectivity for the $3: 2 a$. ${ }^{d}$ Reaction produced a complex mixture of products. 
Utilizing the optimized conditions, we then probed the scope of the reaction by varying the carboxylic acid and amine components (Table 2). Aromatic carboxylic acids including electronneutral (2b-2e), electron-rich (2l) and electron-poor (2k) were tolerated in good yields and regioselectivity. The desired products were furnished in good yields aswell when using aliphatic carboxylic acids ( $\mathbf{2} \mathbf{f}-\mathbf{2 h}$ and $\mathbf{2 j}$ ). Finally, using glycine (2m), acrylic acid (2n), and DIDA ( $N$ dodecyliminodiacetic acid) boronate (2i) all resulted in formation of the rearranged DABN boronates. 
Table 2. Substrate scope, synthesis of DABN boronates $\mathbf{2 a}-\mathbf{2 n}$.

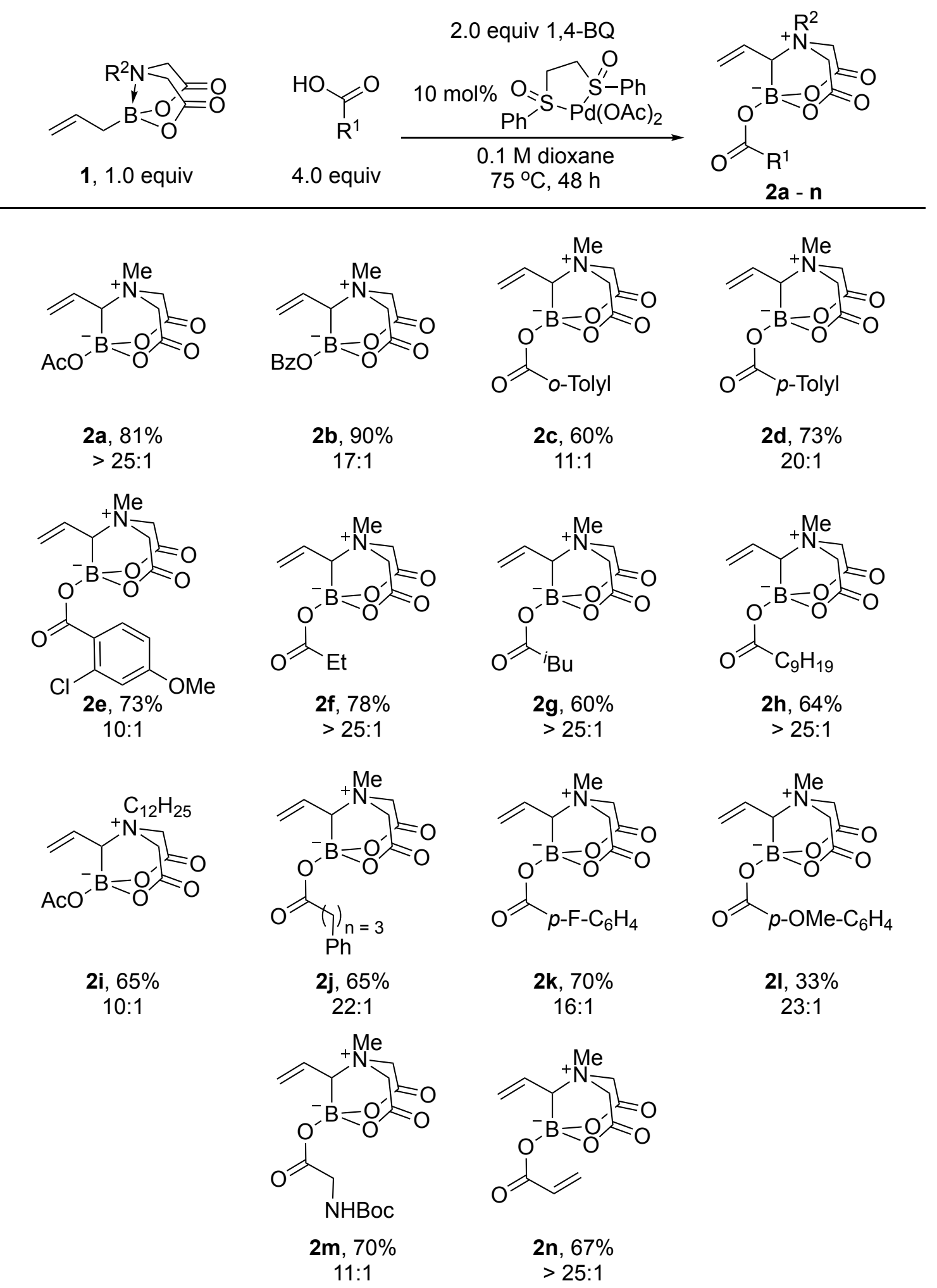


DABN boronates are thermally stable in 1,4-dioxane over a period of 72 hours at $75{ }^{\circ} \mathrm{C}$ as determined by ${ }^{11}$ B NMR spectroscopy (Figure 2A). ${ }^{1514}$ Furthermore, DABN boronates $\mathbf{2 a}-\mathbf{2 n}$ all displayed a diagnostic ${ }^{11} \mathrm{~B}$ NMR chemical shift between $3-4 \mathrm{ppm}$ (Figure 3A), which is considerably upfield of alkyl MIDA boronates that typically appear around $11 \mathrm{ppm}$. Finally, a crystal structure of 2c further confirmed the novel cyclic N-C-B motif (Figure 2A).

a)

Thermal Stability at $75^{\circ} \mathrm{C}$

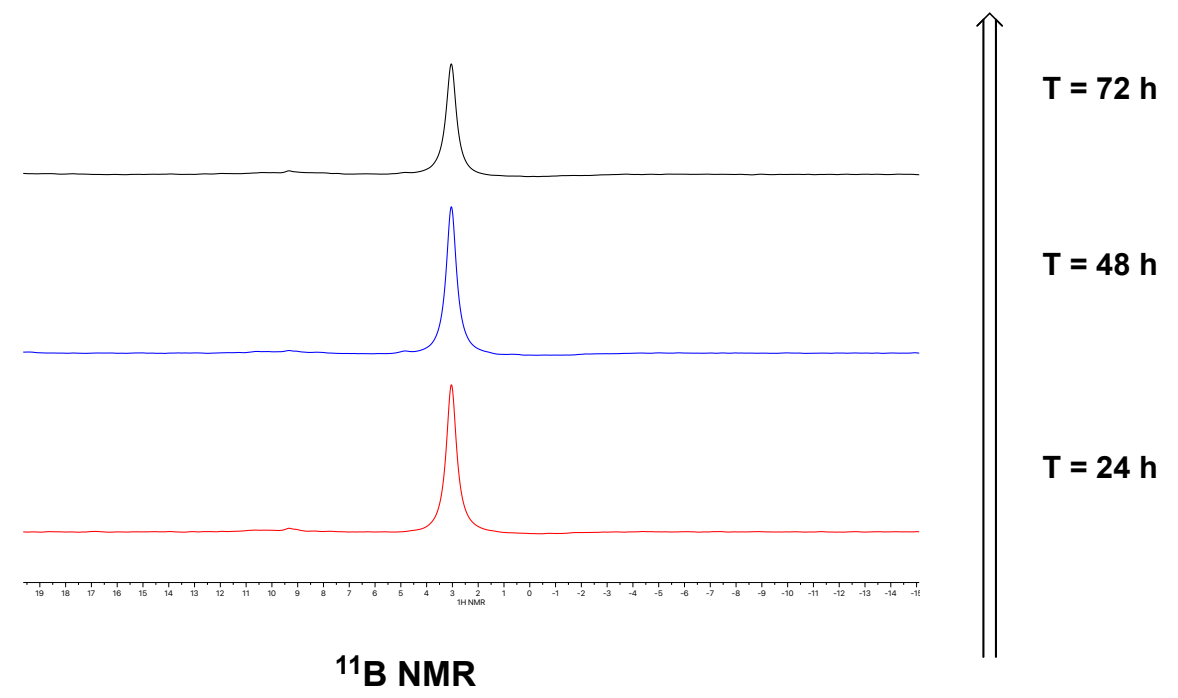

b)

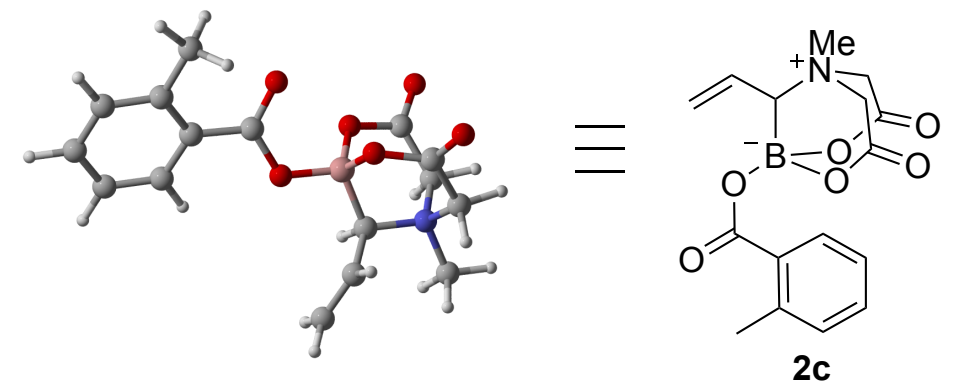

Figure 2. A) Thermal stability of compound 2a. B) X-Ray crystal structure of 2 c.

From a mechanistic standpoint, we envisioned two possible pathways that could lead to comound 2a (Figure 3). The first pathway involves reductive elimination to give $\alpha$-acetoxyboronate (4), which then rearranges to $\mathbf{2 a}$. The instability of $\alpha$-acetoxyboranes and their propensity to undergo a $\mathrm{C} \rightarrow \mathrm{O}$ rearrangement has been previously reported. ${ }^{22}$ In the second pathway, the rearrangement is 
mediated by $\mathrm{Pd}^{\mathrm{II}}$ with the MIDA amine directly intercepting the $\pi$-allyl system to furnish $\mathbf{2 a}$. This mechanism does not involve rearrangement of an intermediate such as $\mathbf{3}$ or $\mathbf{4}$.

To determine which pathway is operative, we carried out a DFT study on this rearrangement at the following level of theory $\operatorname{IEFPCM}_{(1,4-d i o x a n e)} / \mathrm{B} 3 \mathrm{LYP} / 6-311+\mathrm{G}(2 \mathrm{~d}, 2 \mathrm{p}) / \mathrm{B} 3 \mathrm{LYP} / 6-31+\mathrm{G}(\mathrm{d}$,p) with the LanL2DZ basis set for Pd. Both pathways start from INT-A $(0.0 \mathrm{kcal} / \mathrm{mol})$, a palladium-bound $\pi$-allyl species (Figure 3). Pathway 1 (red) involves an initial high-energy reductive elimination (P1-TS1, $28.2 \mathrm{kcal} / \mathrm{mol}$ ) to furnish a palladium-bound $\alpha$-acetoxyboronate (P1-INT1, 15.7 $\mathrm{kcal} / \mathrm{mol})$. Next, dissociation of the catalyst furnishes a slightly higher energy $\alpha$-acetoxyboronate $(4,15.9 \mathrm{kcal} / \mathrm{mol})$ that undergoes acetate mediated $\mathrm{S}_{\mathrm{N}} 2$-attack resulting in displacment of the MIDA amine (P1-TS2, $24.0 \mathrm{kcal} / \mathrm{mol})$ to afford intermediate P1-INT2 $(20.7 \mathrm{kcal} / \mathrm{mol})$, wherein the acetate group forms a covalent bond with boron and the MIDA amine is fully decoordinated. Finally, a high-energy transition state involving $\mathrm{S}_{\mathrm{N}} 2$ attack of the MIDA amine onto the internal carbon $(\mathbf{P 1 - T S 3}, 30.9 \mathrm{kcal} / \mathrm{mol})$ furnishes rearranged DABN boronate $\mathbf{2 a}(-5.1 \mathrm{kcal} / \mathrm{mol})$.

In the second pathway (pathway 2, blue), the first step from INT-A is an $\mathrm{S}_{\mathrm{N}} 2$-attack of the palladium-bound acetate onto boron to displace the MIDA amine (P2-TS1, $15.1 \mathrm{kcal} / \mathrm{mol})$ leading to P2-INT1 (7.9 kcal/mol). This step is considerably lower in energy than P1-TS1 $\left(\Delta \Delta \mathrm{G}^{\neq}=13.1\right.$ $\mathrm{kcal} / \mathrm{mol}$ ). Next, attack of the MIDA amine onto the internal position of the $\pi$-allyl intermediate with concomitant reductive elimination (P2-TS2, $17.6 \mathrm{kcal} / \mathrm{mol})$ leads to P2-INT2 $(6.1 \mathrm{kcal} / \mathrm{mol})$. Finally, dissociation of the catalyst furnishes DABN boronate $2 \mathbf{a}(-5.1 \mathrm{kcal} / \mathrm{mol})$. Our calculations indicate that the second pathway is more likely, and that $\mathbf{2 a}$ does not form from rearrangement of of an intermediate such as $\mathbf{4}$. 


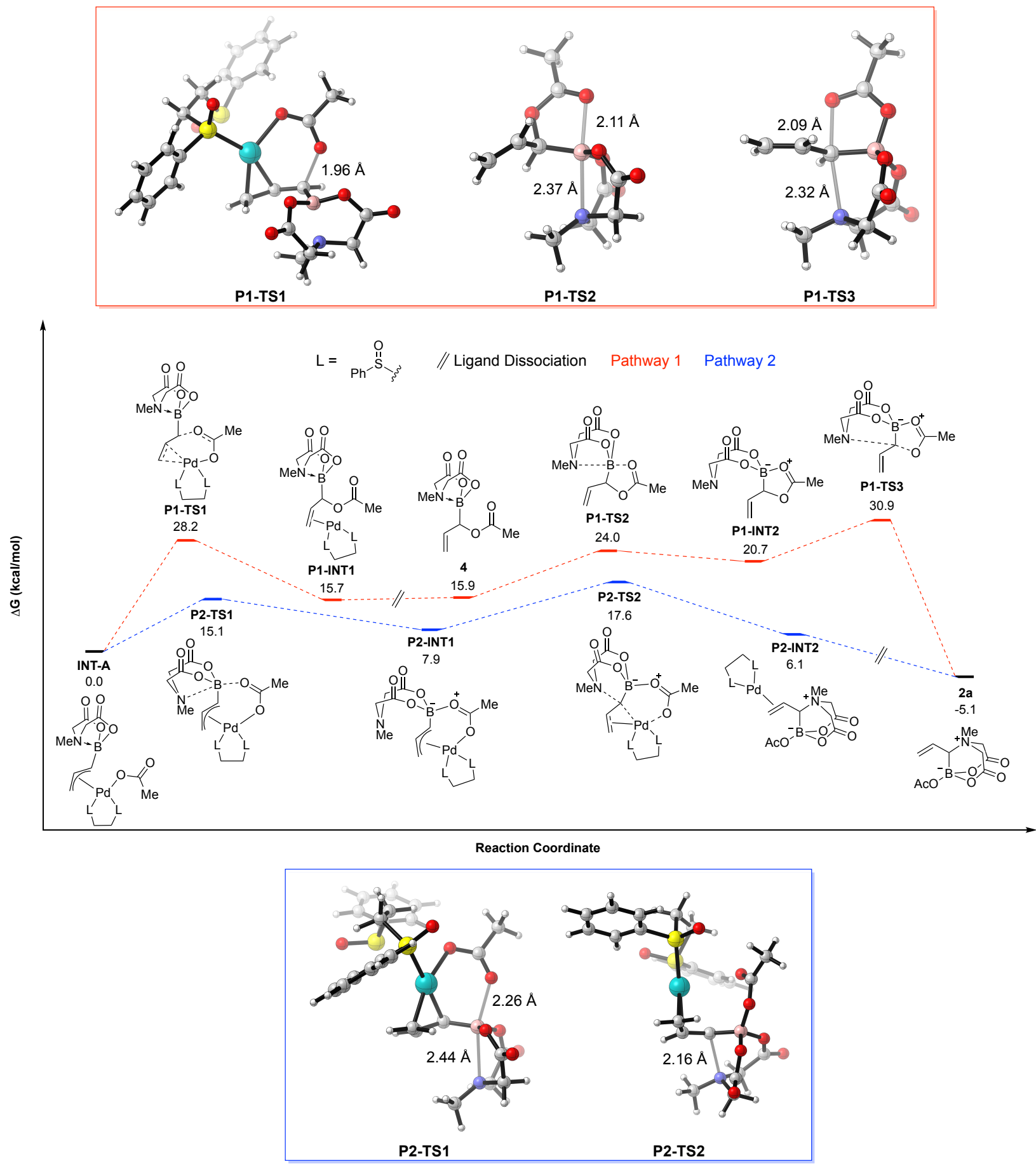

Figure 3. DFT investigation into the possible mechanism of the MIDA boronate rearrangement computed at the B3LYP/6-311+G(2d,2p)//B3LYP/6-31+G(d,p), IEFPCM=1,4-dioxane, with the LanL2DZ basis set for Pd level of theory. 
To further probe the proposed mechanistic pathways, the reaction was monitored by in situ ${ }^{1} \mathrm{H}$ NMR spectroscopy (Figure 4A). We observed that compound 2a began to appear immediately at the start of the reaction, and the rate of formation of the branched product was almost identical to the rate of consumption of the starting material. The $\alpha$-acetoxyboronate (4) was not detected at any point in the course of the reaction. While linear acetate (3) started to appear only near the end of the reaction, it was never present in significant quantities. This finding suggests that compound 2a is not formed from the rearrangement of an intermediate such as $\mathbf{3}$ or $\mathbf{4}$. These results are consistent with pathway 1 being operative.

To rule out the possibility that the linear product is being converted to the branched product by a rapid isomerization mechanism, ${ }^{23,24}$ we separately subjected compounds $\mathbf{2}$ and $\mathbf{4}$ to the reaction conditions. In both cases, no isomerization was observed after 48 hours (Figure 4B). This result, in addition to the theoretical calculations and the NMR investigation, indicates that 2a is formed through pathway 1 (Figure 4). 
a)

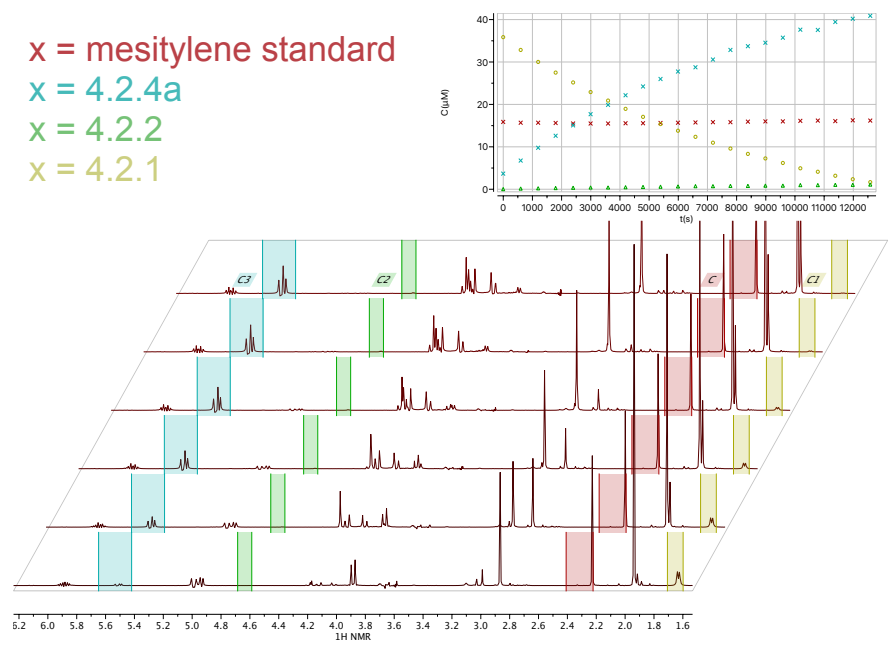

b)
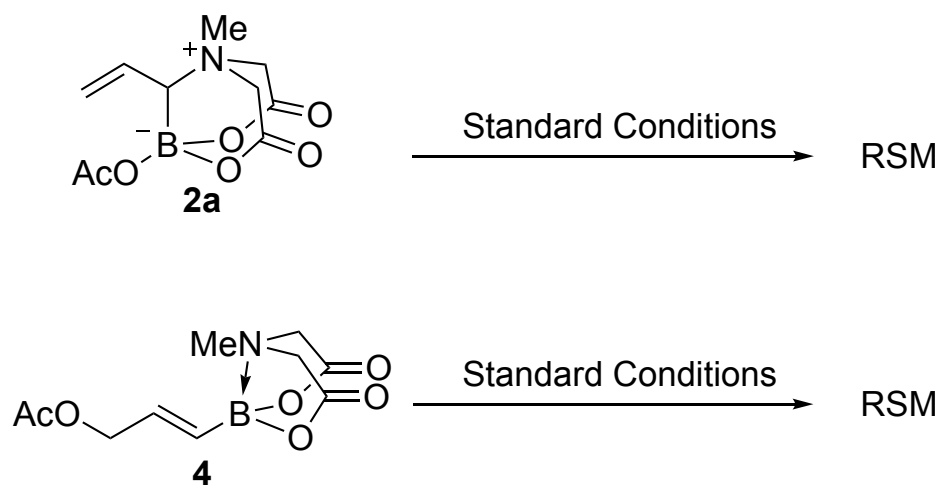

Figure 4. A) Reaction monitoring by in situ ${ }^{1} \mathrm{H}$ NMR over 200 minutes. B) Mechanistic analysis of palladium-catalyzed isomerization.

Due to our previous work in the development of amphoteric $\alpha$-boryl-aldehydes bearing a MIDA ligand, ${ }^{10,25-28}$ we were interested in comparing the stability of the DABN scaffold relative to the MIDA ligand in the ozonolysis of $\mathbf{2}$. Utilizing literature conditions, ${ }^{29,30} \mathbf{2} \mathbf{h}$ was cleanly oxidized to the aldehyde (5a) in 91\% isolated yield (Scheme 2). Three other aldehydes $(\mathbf{5 b}-\mathbf{5 d})$ were synthesized with isolated yields between $70-84 \%$. Crude NMR analysis of the reaction mixtures showed no major byproducts, and the slightly diminished yields can be attributed to difficulties in purifying aldehydes by silica gel chromatography. Aldehydes $\mathbf{5 a}-\mathbf{5 n}$ displayed identical stability to the analogous MIDA-protected derivatives. We did not observe any tautomerization to form the O-bound enolate. 


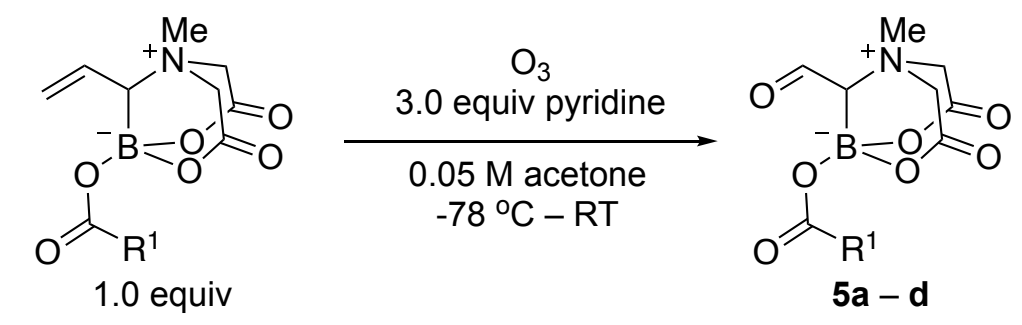

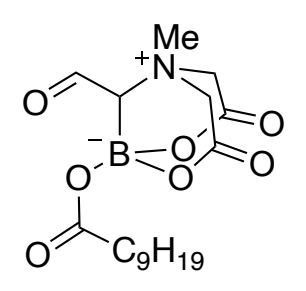

5a, $91 \%$<smiles></smiles>

5c, $70 \%$<smiles>CC(C)CC(=O)O[B-]12OC(=O)C[N+](C)(CC(=O)O1)C2C=O</smiles>

$5 b, 82 \%$<smiles>CN1CC(=O)O[B-]2(OC(=O)c3ccccc3)OC(=O)[C@H]1C2C=O</smiles>

5d, $74 \%$

Scheme 2. Preparation of $\alpha$-boryl aldehydes $(\mathbf{5 a}-\mathbf{5 d})$ by oxidation of DABN allylboronates.

The DABN boronates are configurationally stable under Lewis acidic conditions. Curiosuly, when 2a was treated with $\mathrm{BF}_{3} \cdot \mathrm{OEt}_{2}$ in wet acetonitrile, ${ }^{31}$ we observed displacement of the carboxylate by fluoride to furnish monofluoroborates ( $6 \mathbf{6}$ and $\mathbf{6 b}$ ) in $80 \%$ and $85 \%$ yields, respectively (Figure $5 \mathrm{~A})$. The fact that boron is at the bridgehead position precludes the first dissociation of the acetate because it is not possible for boron to attain the trigonal planar geometry required for $\mathrm{sp}^{2}$ hybridization. ${ }^{32}$ As a result, the fluorination most likely proceeds directly through an $\mathrm{S}_{\mathrm{N}} 2$-like process on the $\mathrm{sp}^{3}$-hybridized boronate. ${ }^{33,34}$ 
A)
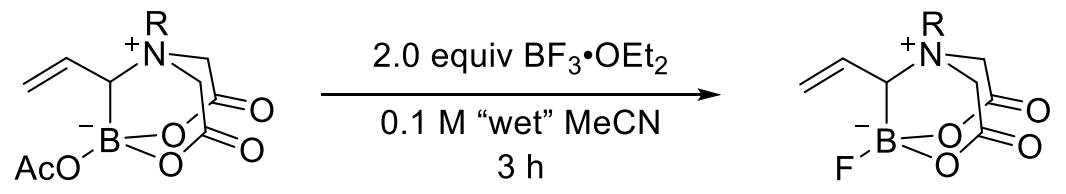

B)

$$
\begin{aligned}
& \text { 2a, } \mathrm{R}=\mathrm{CH}_{3} \\
& \mathbf{2 i}, \mathrm{R}=\mathrm{C}_{12} \mathrm{H}_{25}
\end{aligned}
$$
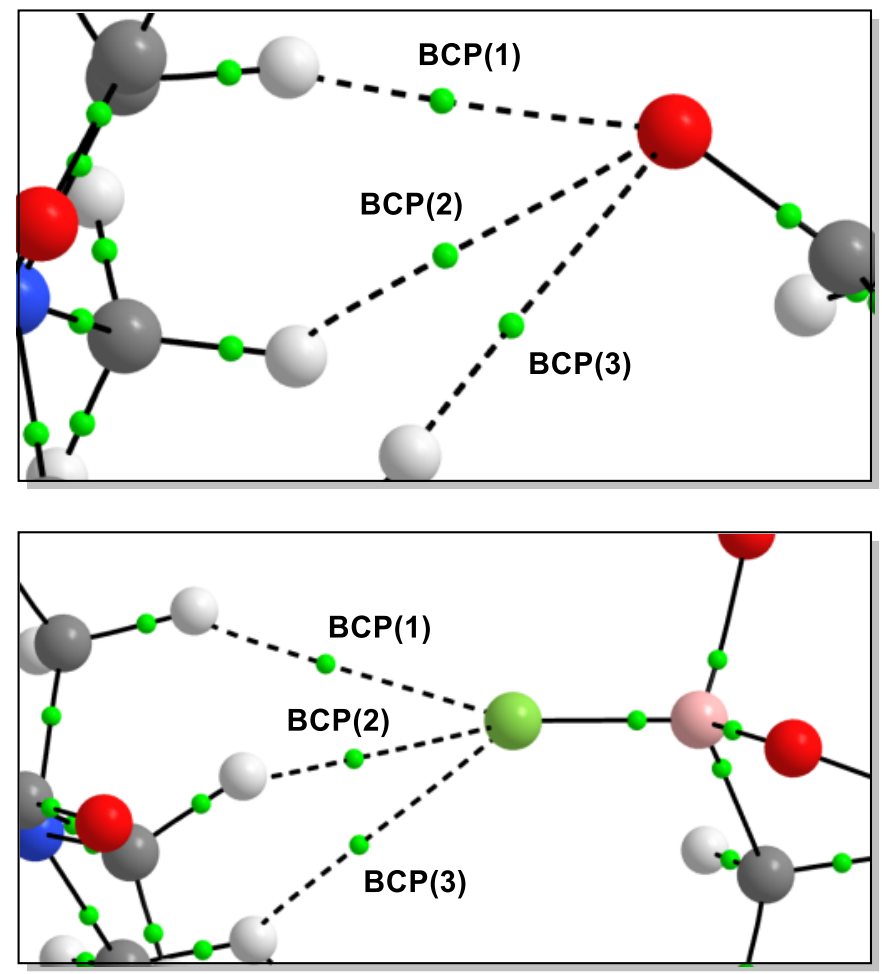

6a, $\mathrm{R}=\mathrm{CH}_{3}, 80 \%$

6b, $\mathrm{R}=\mathrm{C}_{12} \mathrm{H}_{25}, 85 \%$
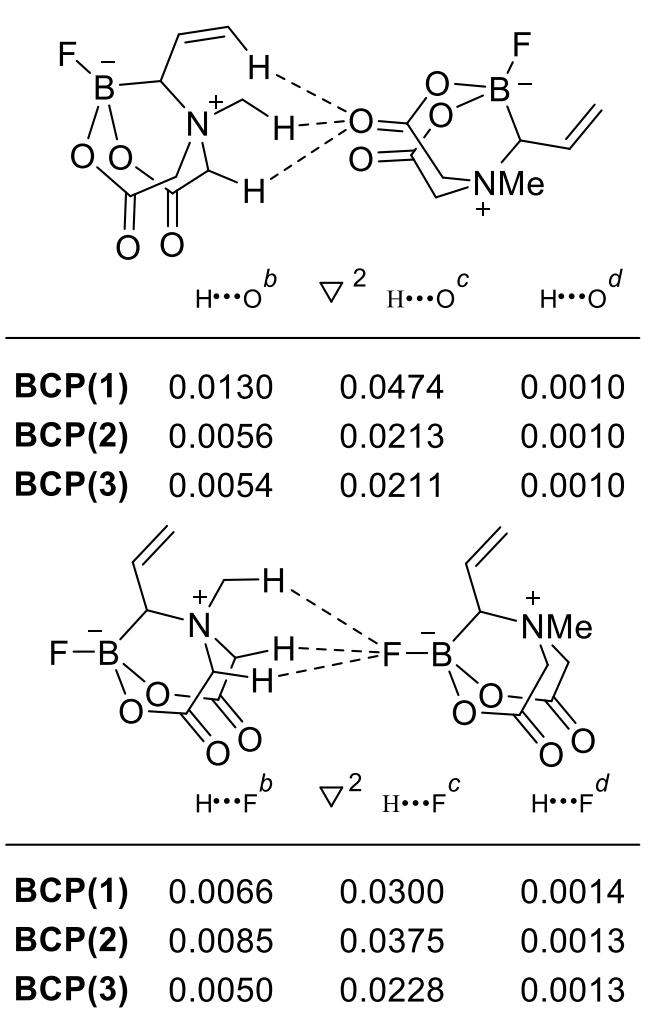

Figure 5. A) Synthesis of monofluoroboronates (6a and 6b). B) Bond critical point (BCP) (+3,1) properties of $\mathrm{H} \bullet \bullet \mathrm{O}$ and $\mathrm{H} \bullet \bullet F$ hydrogen bond interactions present in the crystal structure of 6a. ${ }^{a}$ Atoms in Molecules (AIM) analysis was obtained at the B3LYP/6-31G(d) level of theory. ${ }^{b}$ The electron density at the BCP. ${ }^{\mathrm{c}}$ The Laplacian of the electron density at the BCP. ${ }^{\mathrm{d}}$ The total energy density at the BCP.

X-ray analysis of compound 6a revealed intermolecular C-H hydrogen bonds (Figure 5B) between the methylene hydrogens of DABN and a neighboring fluorine atom (H-bond distance of $2.4 \AA$ ), or a neighboring DABN carbonyl oxygen (H-bond distance of $2.2 \AA$ ). In comparison, this type of intermolecular hydrogen bonding has only been observed once with MIDA boronates, where MIDA capped tellurophenes and selenophenes were shown to self-assemble into rod-like 
hydrogen-bonded porous organic frameworks. ${ }^{35}$ In that case, the intermolecular hydrogen bonds were formed between the MIDA methylene protons and the neighboring oxygen atom of the carbonyl group and varied in length between 2.2 and $2.6 \AA$. No intermolecular C-H hydrogen bonds were observed in the crystal packing of $\mathbf{2 c}$.

Intrigued by the difference between the crystal packing structures of the fluorine and ester derivatives, we investigated the underpinnings of this phenomenon using computation. Atoms in Molecules (AIM) analysis of the crystal structure indicated that there are three $\mathrm{C}-\mathrm{H}$ hydrogen bonds to the fluoride atom, in addition to three $\mathrm{C}-\mathrm{H}$ hydrogens bonds to the carbonyl of the DABN scaffold as seen from the presence of $(+3,-1)$ bond critical points (BCP) (green dots). Based on the topological criteria of the existence of hydrogen bonding proposed by Koch and Popelier and the BCP rho $(\rho)$, Laplacian $\left(\nabla^{2} \rho\right)$ and total electron densities these intereactions all best described as weak hydrogen bonds (Figure 5B). ${ }^{36-38}$ The significant difference between these two compounds indicates that the properties of the DABN ligand can be modulated by the substitution on the boron atom, while still maintaining stability. Furthermore, this is enables the design of novel porous hydrogen-bonded organic frameworks based on DABN hydrogen bonding. ${ }^{35,39-41}$

Since the formation of palladium $\pi$-allyl intermediates from allylammonium species and subsequent derivatization have been previously reported, ${ }^{42-45}$ we envisioned that treatment of $\mathbf{2 a}$ with a suitable $\mathrm{Pd}^{0}$ catalyst would result in oxidative addition into the $\mathrm{C}-\mathrm{N}$ bond of the DABN scaffold. This could then result in the reformation of the MIDA connectivity and the borylated $\pi$ allyl system. To test this, $\mathbf{2 a}$ was treated with stoichiometric $\operatorname{Pd}\left(\mathrm{P}^{t} \mathrm{Bu}_{3}\right)_{2}$. After stirring at room temperature for 16 hours, linear allyl acetate 3 was furnished in 47\% yield (Scheme 3). This rearrangement suggests the intermediacy of a $\pi$-allyl intermediate that can be further functionalized. ${ }^{46-48}$

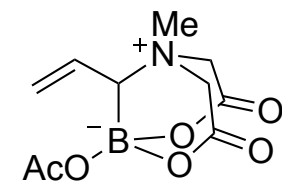

2a, 1.0 equiv

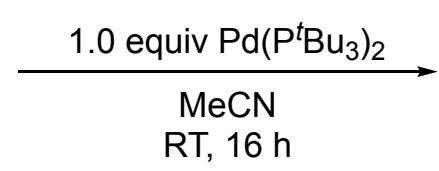

$\mathrm{RT}, 16 \mathrm{~h}$

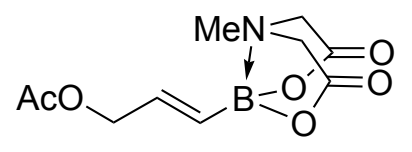

$3,47 \%$

Scheme 3. Rearrangement of 2a to 3 utilizing $\operatorname{Pd}^{0}$. 
We then developed conditions for allylic amination of DABN boronates. Treatment of $\mathbf{2 a}$ with 2.5 $\mathrm{mol} \%[\mathrm{Pd}(\text { allyl }) \mathrm{Cl}]_{2}, 5 \mathrm{~mol}_{\%} \mathrm{PPh}_{3}$ and 2.0 equiv morpholine resulted in formation of the linear amine (7a) in 70\% isolated yield. As expected, MIDA amine coordination to boron is regained, and no degradation of the MIDA moiety was observed. Using these conditions, amino boronates 7a -7 h were synthesized (Scheme 4). Surprisingly, all of the amino boronates were formed with complete linear selectivity.

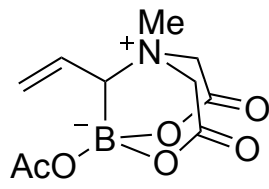

2a, 1.0 equiv

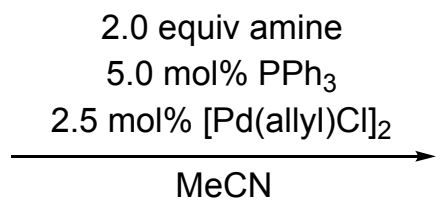

$50{ }^{\circ} \mathrm{C}, 4-16 \mathrm{~h}$

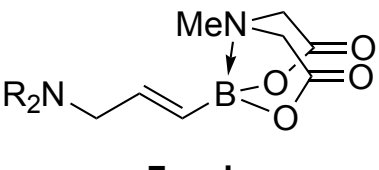

$7 \mathrm{a}-\mathrm{h}$

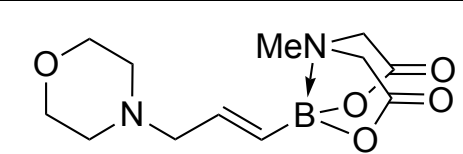

$7 \mathrm{a}, 70 \%$

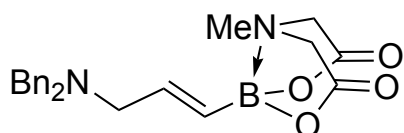

$7 b, 95 \%$

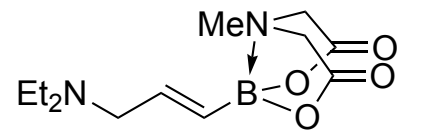

7c, $74 \%$

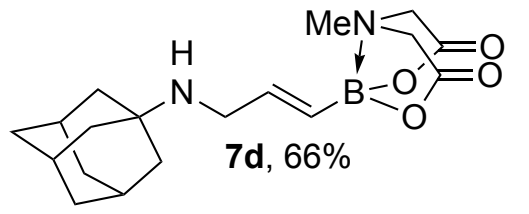<smiles>CN1CC(=O)OB1/C=C/CN1CCc2ccccc2C1</smiles>

$7 e, 68 \%$<smiles>CC1CCN(C/C=C/B2OC(=O)CN(C)C(=O)O2)CC1</smiles>

7f, $60 \%$<smiles>CCCCNCC=C[B-]12CN(CC(=O)O1)CC(=O)O2</smiles>

$7 \mathrm{~g}, 80 \%$

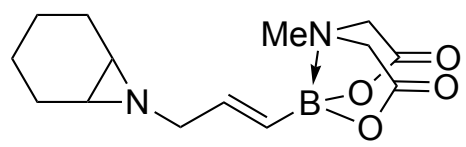

$7 \mathrm{~h}, 68 \%$

Scheme 4. Linear-selective allylic amination of 2a. Synthesis of allyl amino boronates $7 \mathbf{a}-\mathbf{h}$.

Control over regioselectivity in allylic functionalization can be challenging. ${ }^{49-51}$ Our group has previously reported that low regioselectivities in palladium-catalyzed allylic aminations results from a branched-to-linear isomerization to the thermodynamically favored linear product under the reaction conditions. ${ }^{52-54}$ The addition of base prevents this branched-to-linear isomerization 
and enables the isolation of the kinetic branched product. ${ }^{50,51,55-58}$ In this case, the base had no effect on the regioisomeric ratio, and we did not observe any formation of the branched product. That means that unlike our previous findings, linear allyl amino boronates are not formed through a branched-to-linear isomerization. Furthermore, to rule out potential memory effects causing the linear regioselectivity, ${ }^{59-63}$ we carried out the allylic amination utilizing linear acetate $\mathbf{3}$ and observed identical selectivity for the formation of $\mathbf{7 b}$ (Scheme 5).

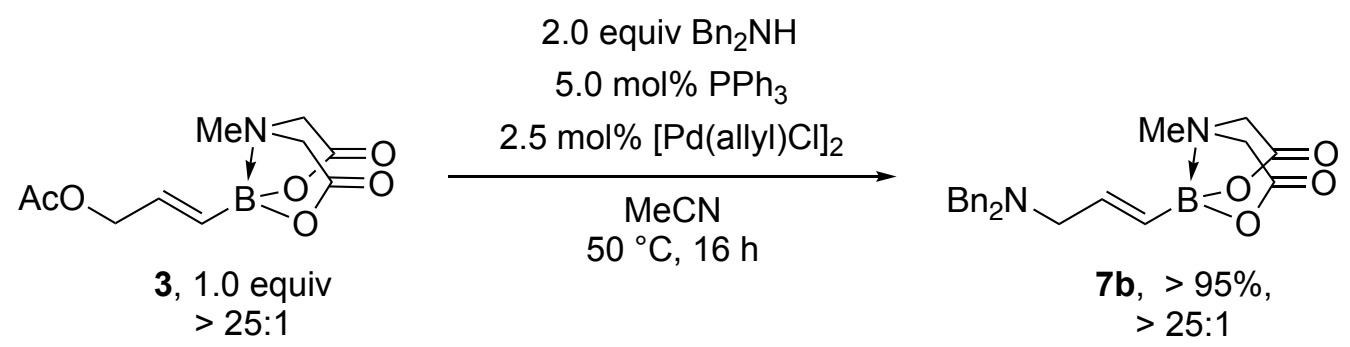

Scheme 5. Allylic amination of $\mathbf{3}$ results in the formation of $\mathbf{7 b}$ with identical regioselectivity.

Due to the exclusive formation of the linear product in the previous examples, and the challenges in obtaining good selectivity in allylic functionalization reactions, we were interested in seeing if the same level of selectivity could be observed with other nucleophiles (Scheme 6). Utilizing sodium azide as the nucleophile furnished the linear boryl azide (8) in $86 \%$ isolated yield, again as the sole regioisomer. Compound $\mathbf{8}$ is stable, and we did not observe any isomerization to the branched azide. The reaction also proceeds in the presence of $\mathrm{PhZnCl} \cdot \mathrm{LiCl}$ to furnish compound 9 in good yield (73\%).

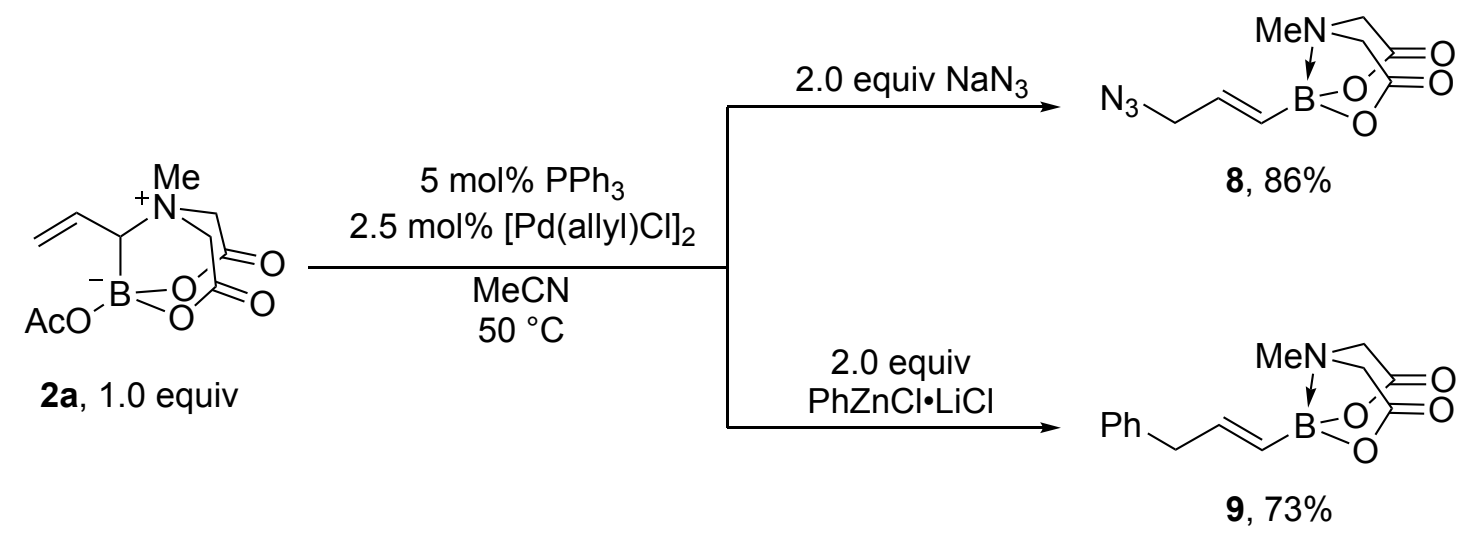

Scheme 6. Linear-selective azidation and arylation of $\mathbf{2 a}$. 
When alkyl zincate $n \mathrm{BuZnCl} \cdot \mathrm{LiCl}$ was utilized, we did not observe the desired alkylated product. Instead, only the reduced products $\mathbf{1 0}$ and $\mathbf{1}$ were formed in an almost equimolar ratio (Scheme 7). These compounds arise from the reduction of the palladium $\pi$-allyl intermediate with hydride. The palladium hydride-species potentially originates from $\beta$-hydride elimination of the alkyl zinc nucleophile. ${ }^{64-67}$ Compound $\mathbf{1 0}$ is formed through the attack of hydride at the terminal position, while 1 is formed from attack at the internal position (branched selectivity). The observation of the branched product (1) when a small nucleophile such as hydride is utilized indicates that the regioselectivity of this reaction for the linear product is likely due to the steric bulk of the DABN/MIDA system.

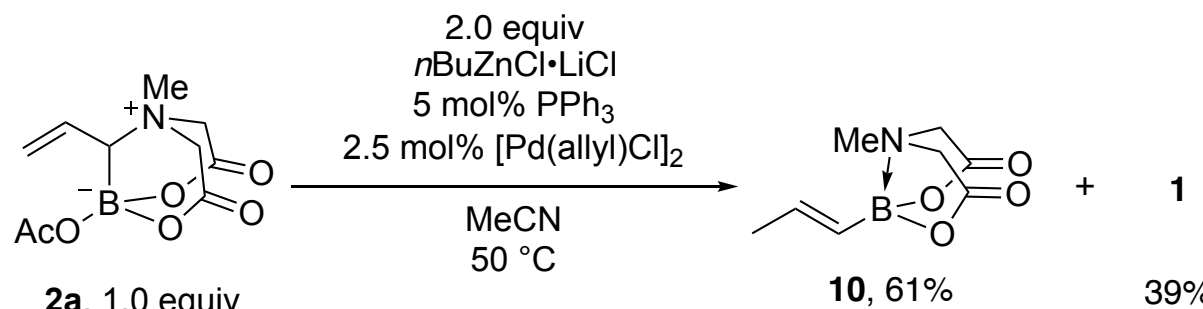

Scheme 7. Attempted alkylation of DABN boronate 2 a results in reduction.

The selectivity of the allylic amination with dimethylamine was investigated by DFT, at the (SMD $=$ acetonitrile $) / \mathrm{B} 3 \mathrm{LYP}-\mathrm{D} 3 \mathrm{BJ} / \mathrm{BS} 2$ with an ultrafine grid level of theory $\left(\mathrm{BS} 2=6-311+\mathrm{G}^{*}\right.$ for $\mathrm{C}$, $\mathrm{H}, \mathrm{O}, \mathrm{B}, \mathrm{N} ; \mathrm{6}-311++\mathrm{G}^{* *}$ for P; and Def2-TZVPP with ECP for Pd). Emerging from these calculations were two structures corresponding to the lowest energy transition states leading to the linear and branched products, respectively (Figure 6). The relative free energy barriers of TSLinear and TS-Branched were computed to be 9.8 and $13.3 \mathrm{kcal} / \mathrm{mol}$, respectively, with the TSlinear being favored by $3.7 \mathrm{kcal} / \mathrm{mol}$. This is different from the linear and branched transition states in di-alkyl substituted $\pi$-allyl systems which were shown to be energetically similar $(\Delta \mathrm{G}<$ $1 \mathrm{kcal} / \mathrm{mol}) .{ }^{56}$ The bulkiness of the MIDA ligand contributes large steric contact with the incoming nucleophile, as seen by a $\mathrm{H} \cdots \mathrm{H}$ distance of $2.3 \AA$ in TS-Branched, (MIDA boronate A-value = 2.4). ${ }^{68}$ In addition to this, Natural Bond Orbital (NBO) analysis revealed two donor-acceptor interactions that stabilize TS-Linear. The first stabilizing interaction is from the $d$-orbital of Pd to boron's empty $p$-orbital, amounting to $11.3 \mathrm{kcal} / \mathrm{mol}$ of stabilization. Also present was a smaller in magnitude donor-acceptor interaction $(\mathrm{C}-\mathrm{B}) \rightarrow(\mathrm{Pd})^{*}$, which provides a modest $1.0 \mathrm{kcal} / \mathrm{mol}$ of 
stabilization energy. These calculations corroborate our experimental observation that the linear allyl amino boronate is both the kinetic and thermodynamic product.

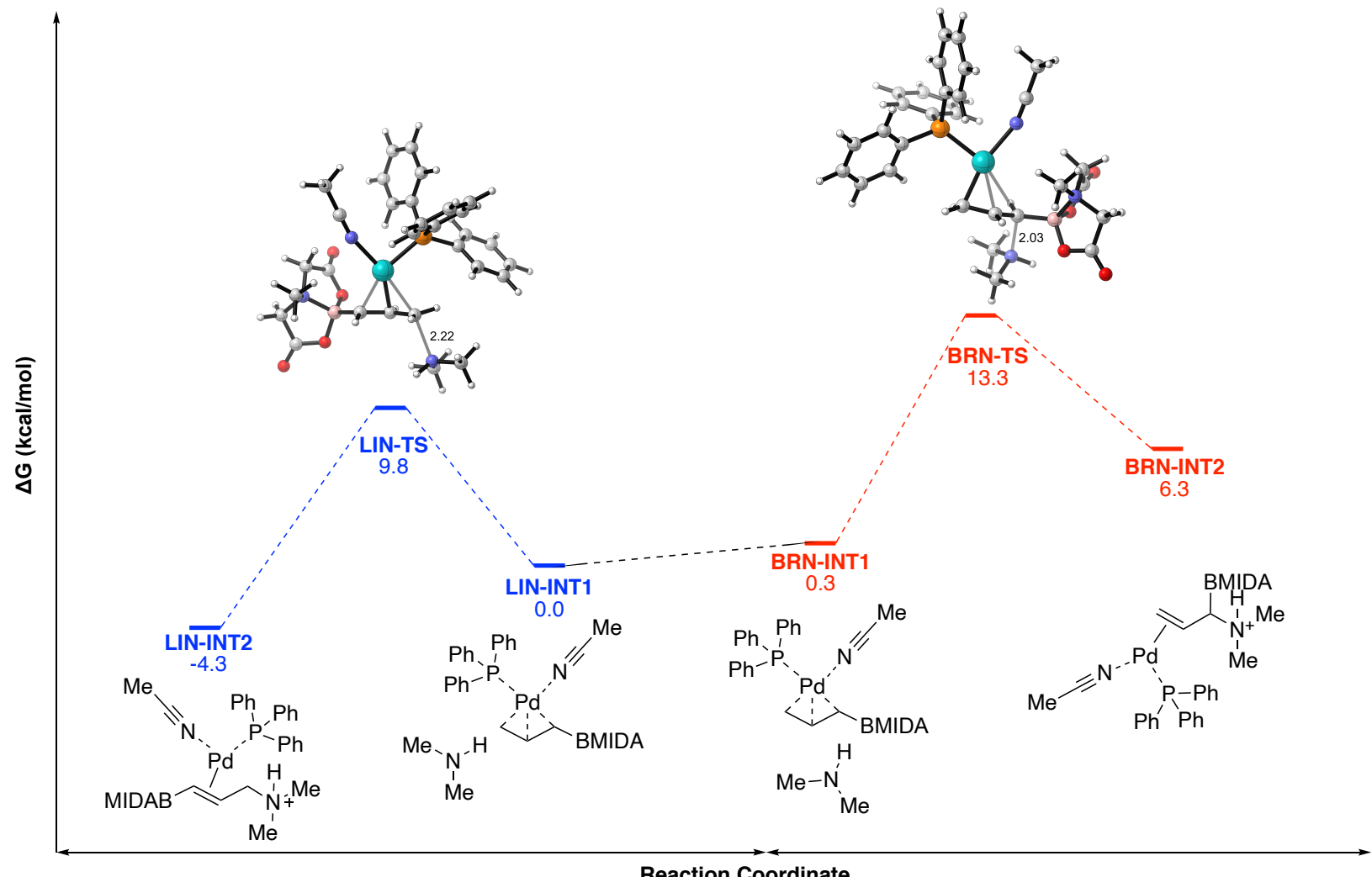

Figure 6. Lowest energy linear and branched transition states for the regioselective attack of dimethylamine on the palladium $\pi$-allyl system derived from 2a (B3LYP/GENECP (SMD = acetonitrile)).

Given our previous observations that the MIDA moiety directs the reaction, we then examined the role of amine on the linear/branched selectivity by utilizing ammonia and diethylamine (Figure 7). In the case of ammonia, the branched transition state is $3.3 \mathrm{kcal} / \mathrm{mol}$ higher in energy than the corresponding linear transition state. This scenario is similar to the case of dimethylamine, where the branched transition state is $3.7 \mathrm{kcal} / \mathrm{mol}$ higher (Figure 6). In respect to steric bulk, both ammonia and dimethylamine have similar A-values (1.9 and 2.1), thus we would not expect to see a large difference for the $\Delta \mathrm{G}^{\ddagger}$. On the other hand, with diethylamine, we see that the extra bulk of the two methyl groups have a significant impact: with the linear transition state being favored by $6.6 \mathrm{kcal} / \mathrm{mol}$, which is double that of ammonia. We can see that as the steric bulk of the nucleophile increases, so does the preference for an attack at the linear position, distal from the MIDA unit. 
This indicates that sterics of the MIDA unit play an essential role in directing regioselectivity and that unlike previous palladium-catalyzed reactions, a branched-to-linear isomerization is unlikely.

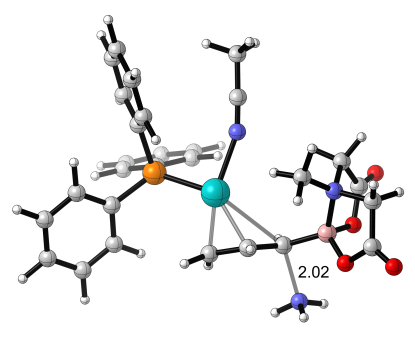

BRN-TS-NH 3

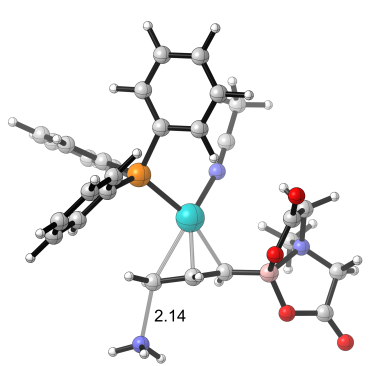

LIN-TS-NH 3

$\Delta \Delta \mathrm{G}^{\ddagger}$ linear vs. branched $=3.3 \mathrm{kcal} / \mathrm{mol}$

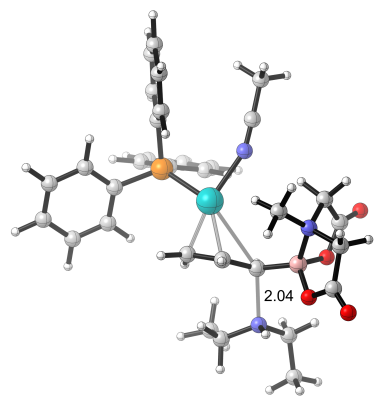

BRN-TS-Et ${ }_{2} \mathrm{NH}$

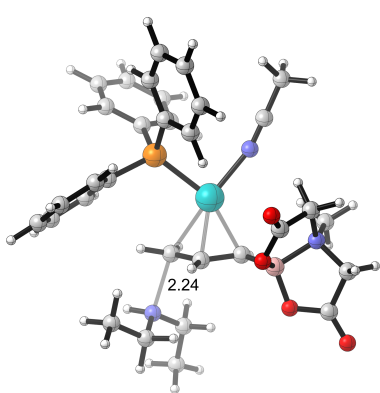

LIN-TS-Et ${ }_{2}$ NH

$\Delta \Delta \mathrm{G}^{\ddagger}$ linear vs. branched $=6.6 \mathrm{kcal} / \mathrm{mol}$

Figure 7. Linear and branched transition states for allylic amination with ammonia and diethylamine $\left(\Delta \Delta \mathrm{G}^{\ddagger} \mathrm{kcal} / \mathrm{mol}, \mathrm{B} 3 \mathrm{LYP} / \mathrm{GENECP}(\mathrm{SMD}=\right.$ acetonitrile $\left.)\right)$.

Based on our ability to functionalize the DABN scaffold, we envisioned a sequential 3-component coupling of both the nucleophilic and electrophilic nodes could be possible (Scheme 8). Using the optimized catalyst system from the allylic amination in the presence of 4-bromoanisole and aqueous $\mathrm{K}_{3} \mathrm{PO}_{4}$, we observed the formation of the allyl-difunctionalized compound 11a in $64 \%$ isolated yield (Scheme 8). The sequential electrophilic and nucleophilic reactivity enables 2a to function as a linchpin, thus allowing the rapid assembly of drug-like molecules. For example, utilizing this methodology, we were able to synthesize cinnarizine (11c, 51\%) and naftifine (11d, $62 \%$ ) in just two steps from only commercially available starting materials. 


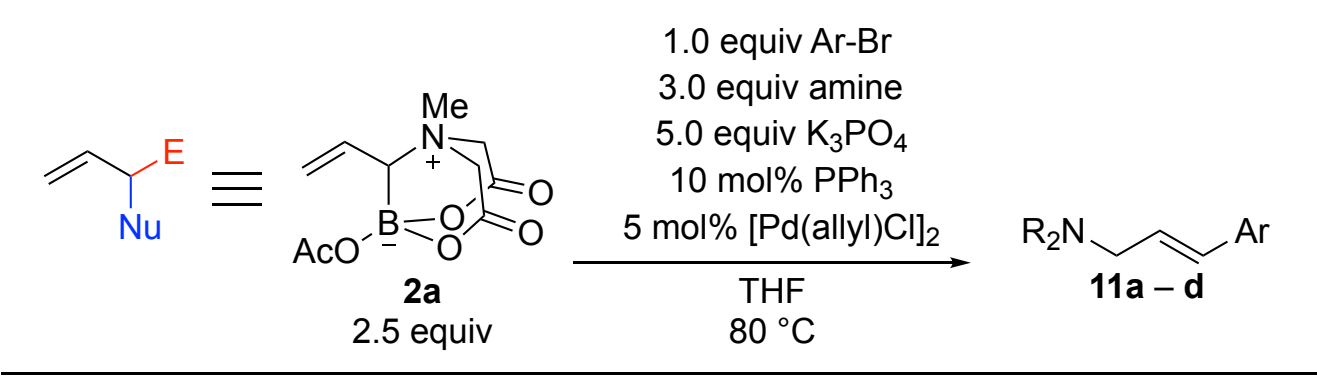

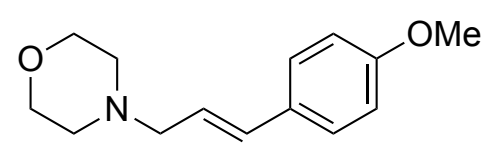

$11 \mathrm{a}, 64 \%$

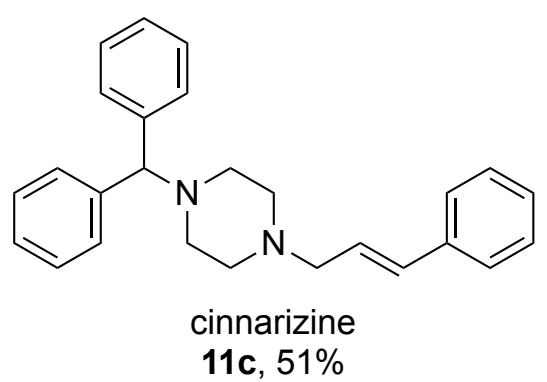<smiles>CCN(CC)C/C=C/c1ccccc1C</smiles>

11b, $69 \%$

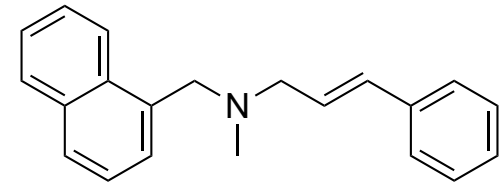

naftifine

$11 \mathrm{~d}, 62 \%$

Scheme 8. 3-Component coupling of 2a towards the synthesis of cinnarizine (11c) and naftifine (11d).

\section{Conclusion}

In summary, we have demonstrated that the versatility of MIDA ligand extends beyond its ability to function as a protecting group. By building on our previous report on MIDA hemilability, we have shown that the MIDA amine can behave as a nucleophile to intercept $\pi$-allyl intermediates and furnish allylammonium DABN boronates. Mechanistic and DFT investigations show that this transformation proceeds through a palladium-catalyzed $\mathrm{S}_{\mathrm{N}} 2$ on tetrasubstituted boron.

We have further demonstrated that this reaction is reversible: treatment with $\mathrm{Pd}^{0}$ results in oxidative insertion into the carbon-ammonium bond, reforming the $\pi$-allyl system, which can then react with an external nucleophile to form linear functionalized vinyl boronates with complete regioselectivity. Unlike previous allylic aminations catalyzed by palladium, the linear product is both the kinetic and thermodynamic product in this case and does not form from branched-tolinear isomerization. Furthermore, a 3-component coupling was developed to regioselectively furnish linear borylated allylamines. By leveraging this methodology, pharmaceuticals naftifine and cinnarizine were synthesized in just two steps from commercially available starting materials. 
The benefit of this approach is that the boronate is still available to undergo cross-coupling leading to products with complete linear regioselectivity. DFT calculations indicated that the regiocontrol of the allylic functionalization reactions comes from the steric bulk of the MIDA moiety directing the nucleophile to the less hindered terminal position. Finally, this work reports a previously unknown aspect of MIDA instability that can now be exploited in other transition metal-catalyzed reactions.

\section{Acknowledgements}

We thank the Natural Science and Engineering Research Council (NSERC) for funding. S.J.K thanks NSERC CGS-D. We acknowledge NSERC and the Canadian Foundation for Innovation, Project 19119, and the Ontario Research Fund for funding of the Centre for Spectroscopic Investigation of Complex Organic Molecules and Polymers. Dr. A. Lough (University of Toronto) is thanked for X-ray structural analysis. G. P. G gratefully acknowledges NSERC for the Banting

Postdoctoral Fellowship and the Defense Advanced Research Projects Agency under the Accelerated Molecular Discovery Program under Cooperative Agreement No. HR00111920027 dated August 1, 2019. The content of the information presented in this work does not necessarily reflect the position or the policy of the Government. We thank Professor Alán Aspuru-Guzik (University of Toronto and Vector Institute for Artificial Intelligence) for providing support to G.P.G. We thank Compute Canada for computational resources. DFT and NBO computations were performed on the niagara supercomputer at the SciNet HPC Consortium. SciNet is funded by: the Canada Foundation for Innovation; the Government of Ontario; Ontario Research Fund - Research Excellence; and the University of Toronto.

\section{References}

(1) Mancilla, T.; Contreras, R.; Wrackmeyer, B. J. Organomet. Chem. 1986, 307, 1-6.

(2) Garrigues, B.; Mulliez, M.; Raharinirina, A. J. Organomet. Chem. 1986, 302, 153-158.

(3) Gillis, E. P.; Burke, M. D. J. Am. Chem. Soc. 2007, 129, 6716-6717.

(4) Dick, G. R.; Woerly, E. M.; Burke, M. D. Angew. Chem. Int. Ed. 2012, 51, 2667-2672.

(5) Li, J.; Ballmer, S. G.; Gillis, E. P.; Fuji, S.; Schmidt, M. J.; Palazzolo, A. M. E.; Lehmann, J. W.; Morehouse, G. F.; Burke, M. D. Science 2015, 347, 1221-1226.

(6) St, D.; Lee, C. F.; Yudin, A. K. Org. Lett. 2015, 17, 5764-5767.

(7) St Denis, J. D.; Scully, C. C. G.; Lee, C. F.; Yudin, A. K. Org. Lett. 2014, 16, 1338-1341.

(8) Kaldas, S. J.; O'Keefe, K. T. V.; Mendoza-Sanchez, R.; Yudin, A. K. Chem. Eur. J. 2017, 23, 9711-9715. 
(9) Shao, W.; Kaldas, S. J.; Yudin, A. K. Chem. Sci. 2017, 8, 4431-4436.

(10) Kaldas, S. J.; Rogova, T.; Nenajdenko, V. G.; Yudin, A. K. J. Org. Chem. 2018, 83, 7296-7302.

(11) Gillis, E. P.; Burke, M. D. Aldrichimica Acta 2009, 42, 17-27.

(12) Gonzalez, J. A.; Ogba, O. M.; Morehouse, G. F.; Rosson, N.; Houk, K. N.; Leach, A. G.; Cheong, P. H.-Y.; Burke, M. D.; Lloyd-Jones, G. C. Nat. Chem. 2016, 8, 1-9.

(13) Woerly, E. M.; Cherney, A. H.; Davis, E. K.; Burke, M. D. J. Am. Chem. Soc. 2010, 132, 6941-6943.

(14) Cox, P. A.; Leach, A. G.; Campbell, A. D.; Lloyd-Jones, G. C. J. Am. Chem. Soc. 2016, 138, 9145-9157.

(15) Cox, P. A.; Reid, M.; Leach, A. G.; Campbell, A. D.; King, E. J.; Lloyd-jones, G. C. J. Am. Chem. Soc. 2017, 13156-13165.

(16) Lee, C. F.; Diaz, D. B.; Holownia, A.; Kaldas, S. J.; Liew, S. K.; Garrett, G. E.; Dudding, T.; Yudin, A. K. Nat. Chem. 2018, 10, 1062-1070.

(17) Holownia, A.; Tien, C. H.; Diaz, D. B.; Larson, R. T.; Yudin, A. K. Angew. Chemie - Int. Ed. 2019, 58, 15148-15153.

(18) Chen, M. S.; White, M. C. J. Am. Chem. Soc. 2004, 126, 1346-1347.

(19) Chen, M. S.; Prabagaran, N.; Labenz, N. A.; White, M. C.; Chen, M. S.; Prabagaran, N.; Labenz, N. A.; White, M. C. J. Am. Chem. Soc. 2005, 127, 6970-6971.

(20) Osberger, T. J.; White, M. C. J. Am. Chem. Soc. 2014, 136, 11176-11181.

(21) Ma, R.; Young, J.; Promontorio, R.; Dannheim, F. M.; Pattillo, C. C.; White, M. C. J. Am. Chem. Soc. 2019, 141, 9468-9473.

(22) Hubbard, J. L. J. Organomet. Chem. 1993, 445, 7-9.

(23) Overman, L. E.; Knoll, F. M. Tetrahedron Lett. 1979, 20, 321-324.

(24) Shekhar, S.; Trantow, B.; Leitner, A.; Hartwig, J. F. J. Am. Chem. Soc. 2006, 128, 11770 11771.

(25) He, Z.; Yudin, A. K. J. Am. Chem. Soc. 2011, 133, 13770-13773.

(26) St. Denis, J. D.; Zajdlik, A.; Tan, J.; Trinchera, P.; Lee, C. F.; He, Z.; Adachi, S.; Yudin, A. K. J. Am. Chem. Soc. 2014, 136, 17669-17673.

(27) Tan, J.; Yudin, A. K. Drug Discov. Today Technol. 2018, 29, 51-60.

(28) Tan, J.; Cognetta, A. B. I.; Diaz, D. B.; Lum, K. M.; Adachi, S.; Kundu, S.; Cravatt, B. F.; Yudin, A. K. Nat. Commun. 2017, 8, 1760-1768.

(29) Taguchi, J.; Ikeda, T.; Takahashi, R.; Sasaki, I.; Ogasawara, Y.; Dairi, T.; Kato, N.; Yamamoto, Y.; Bode, J. W.; Ito, H. Angew. Chem. Int. Ed. 2017, 56, 13847-13851.

(30) Willand-Charnley, R.; Fisher, T. J.; Johnson, B. M.; Dussault, P. H. Org. Lett. 2012, 14, 2242-2245.

(31) Askin, D.; Angst, C.; Danishefsky, S. J. Org. Chem. 1987, 52, 622-635.

(32) Alabugin, I. V.; Bresch, S.; Dos Passos Gomes, G. J. Phys. Org. Chem. 2015, 28, $147-$ 162.

(33) Dai, W.; Geib, S. J.; Curran, D. P. J. Am. Chem. Soc. 2019, 141, 3623-3629.

(34) Denmark, S. E.; Nishide, K.; Faucher, A. M. J. Am. Chem. Soc. 1991, 113, 6675-6676.

(35) Li, P. F.; Qian, C.; Lough, A. J.; Ozin, G. A.; Seferos, D. S. Dalt. Trans. 2016, 45, 97549757.

(36) Koch, U.; Popelier, P. L. A. J. Phys. Chem. 1995, 99, 9747-9754.

(37) Parthasarathi, R.; Subramanian, V.; Sathyamurthy, N. J. Phys. Chem. A 2006, 110, 33493351. 
(38) Rozas, I.; Alkorta, I.; Elguero, J. J. Am. Chem. Soc. 2000, 122, 11154-11161.

(39) Hisaki, I.; Xin, C.; Takahashi, K.; Nakamura, T. Angew. Chem. Int. Ed. 2019, 58, 1116011170.

(40) Lin, R. B.; He, Y.; Li, P.; Wang, H.; Zhou, W.; Chen, B. Chem. Soc. Rev. 2019, 48, 13621389.

(41) Luo, J.; Wang, J. W.; Zhang, J. H.; Lai, S.; Zhong, D. C. CrystEngComm 2018, 20, 58845898.

(42) Doi, T.; Yanagisawa, A.; Miyazawa, M.; Yamamoto, K. Tetrahedron: Asymmetry 1995, 6 , 389-392.

(43) Hirao, T.; Yamada, N.; Ohshiro, Y.; Agawa, T. J. Organomet. Chem. 1982, 236 (3), 409414.

(44) Yamamoto, T.; Akimoto, M.; Saito, O.; Yamamoto, A. Organometallics 1986, 5 (8), 1559-1567.

(45) Trost, B. M.; Keinan, E. J. Org. Chem. 1980, 45, 2741-2746.

(46) Touchet, S.; Carreaux, F.; Molander, G. A.; Carboni, B.; Bouillon, A. Adv. Synth. Catal. 2011, 353, 3391-3396.

(47) Potter, B.; Szymaniak, A. A.; Edelstein, E. K.; Morken, J. P. J. Am. Chem. Soc. 2014, 136, 17918-17921.

(48) Edelstein, E. K.; Namirembe, S.; Morken, J. P. J. Am. Chem. Soc. 2017, 139, 5027-5030.

(49) Madrahimov, S. T.; Li, Q.; Sharma, A.; Hartwig, J. F. J. Am. Chem. Soc. 2015, 137, $14968-14981$.

(50) Dubovyk, I.; Watson, I. D. G.; Yudin, A. K. J. Org. Chem. 2013, 78, 1559-1575.

(51) Watson, I. D. G. G.; Yudin, A. K. J. Am. Chem. Soc. 2005, 127, 17516-17529.

(52) Faller, J. W.; Wilt, J. C. Organometallics 2005, 24, 5076-5083.

(53) Nilsson, Y. I. M.; Andersson, P. G.; Bäckvall, J. E. J. Am. Chem. Soc. 1993, 115, 66096613.

(54) Vitagliano, A.; Åkermark, B. J. Organomet. Chem. 1988, 349, C22-C26.

(55) Dubovyk, I.; Watson, I. D. G. G.; Yudin, A. K. J. Am. Chem. Soc. 2007, 129, $14172-$ 14173.

(56) Iuliis, M. Z. De; Watson, I. D.; Yudin, A. K.; Morris, R. H. Can. J. Chem. 2008, 87, 5462.

(57) Dubovyk, I.; Pichugin, D.; Yudin, A. K. Angew. Chem. Int. Ed. 2011, 50, 5924-5926.

(58) Pattillo, C. C.; Strambeanu, I. I.; Calleja, P.; Vermeulen, N. A.; Mizuno, T.; White, M. C. J. Am. Chem. Soc. 2016, 138, 1265-1272.

(59) Milheiro, S. C.; Faller, J. W. J. Organomet. Chem. 2011, 696, 879-886.

(60) Faller, J. W.; Sarantopoulos, N. Organometallics 2004, 23, 2179-2185.

(61) Faller, J. W.; Wilt, J. C. Org. Lett. 2005, 7, 633-636.

(62) Evans, P. A.; Nelson, J. D. J. Am. Chem. Soc. 1998, 120, 5581-5582.

(63) Lloyd-Jones, G. C.; Stephen, S. C. Chem. - A Eur. J. 1998, 4, 2539-2549.

(64) Alexanian, E. J.; Hartwig, J. F. J. Am. Chem. Soc. 2008, 130, 15627-15635.

(65) Miyaura, N.; Ishiyama, T.; Ishikara, M.; Suzuki, A. Tetrahedron Lett. 1986, 27, 63696372.

(66) Frisch, A. C.; Beller, M. Angew. Chem. Int. Ed. 2005, 44, 674-688.

(67) Blum, O.; Milstein, D. J. Am. Chem. Soc. 1995, 117, 4582-4594.

(68) Corless, V. B.; Holownia, A.; Foy, H.; Mendoza-Sanchez, R.; Adachi, S.; Dudding, T.; Yudin, A. K. Org. Lett. 2018, 20, 5300-5303. 